Vol. 11, No. 1, 2021

\title{
ANALYSIS OF MAGNETIC FIELDS OF ELECTRICAL DEVICES BASED ON THEIR CIRCUIT MODELS
}

\author{
Vsevolod Horyachko, Orest Hamola, Taras Ryzhyi \\ Lviv Polytechnic National University, Lviv, Ukraine \\ vsevolod.i.horiachko@lpnu.ua,orest.y.hamola@lpnu.ua,taras-oleh.i.ryzhyi@lpnu.ua
}

\begin{abstract}
The article deals with an analysis of magnetic fields of electric machines and electromagnetic devices on the basis of their circuit mathematical models. The magnetic systems of electrical devices in these models are presented in the form of planar nonlinear magnetic circuits with lumped elements. The parameters of these elements are determined on the basis of geometric dimensions taking into account the design features of the devices and the physical parameters of the environment.
\end{abstract}

Key words: electric machine, transformer, mathematical model, magnetic circuit, magnetic field, magnetic field induction

\section{Introduction}

Given the increasing complexity of power transmission and control systems operating modes, the requirements for the adequacy of mathematical models of their structural elements (transformers, autotransformers, reactors, and synchronous turbogenerators) are becoming higher [1].

Mathematical models of such objects, developed on the basis of the theory of the electromagnetic field, cannot always provide high calculation adequacy. This is due to the difficulties that arise in determining boundary conditions and applying numerical methods to highdimensional problems [3]. In addition, most of these models allow modeling the field only in two-dimensional space for given currents and fixed positions of moving parts of electric machines [2].

Mathematical models of electrical devices, implemented using the theory of electromagnetic circuits are much more economical. However, due to the large number of assumptions, they do not always provide appropriate adequacy. In most of such models, the magnetic fluxes are divided into main and leakage ones based on their independence. It should be noted that the modelling of electrical devices is determined by modelling their complex magnetic system.

The development of highly efficient and adequate circuit mathematical models for electrical devices analysis as complex nonlinear dynamic electromagnetic systems remains an actual and promising task. With an adequate representation of their magnetic systems, it is possible to obtain the magnetic field parameters that can be used in the design and study of operating modes of these objects.

\section{Mathematical formulation of the task}

In the mathematical models of electrical devices proposed in [4] with their complex electromagnetic connections, magnetic systems are presented in the form of a planar nonlinear magnetic circuit with a single magnetic flux without its division into the main and leakage. Lumped elements of the circuit are equivalent to the elementary volumes into which the space of electrical devices is divided. The parameters of these elements are determined based on geometric dimensions and physical characteristics of the environment.

Given a certain symmetry of the magnetic fields of electromagnetic devices and electric machines, the space of electrical devices, which includes magnetic conductors and air, is divided so as to obtain a calculation scheme of the magnetic circuit in the form of a two-dimensional planar grid.

Considering the magnetic field of electric machines to be plane-parallel, it is expedient to divide the space of the electric machine into elementary volumes by concentric surfaces and diametrical planes along the entire length of the machine. For transformers and other electromagnetic devices, the magnetic field is symmetrical relative to the axes of the magnetic core rods. In this case, the division of space is carried out by cylindrical surfaces relative to the axes of the rods and planes perpendicular to them.

Fig. 1-3 show the methods of dividing the space and the scheme of the magnetic circuits of the transformer with an armored magnetic core and a synchronous turbogenerator.

As a result of such space division, we will obtain elementary volumes (Fig. 4) in the form of thin-walled half-cylinders (for electromagnetic devices) and sectors of thin-walled cylinders (for electric machines).

Areas of space that include the magnetic circuit are represented in the magnetic circuit by nonlinear magnetic resistances, and air areas - by linear magnetic resistances. If the zone of elementary volume includes not only a part of the magnetic circuit, but also a section with non-ferromagnetic material, then in this case this volume is given in the circuit by one nonlinear magnetic resistance. To do this, we use equivalence formulas for different ways of connecting magnetic resistances. 

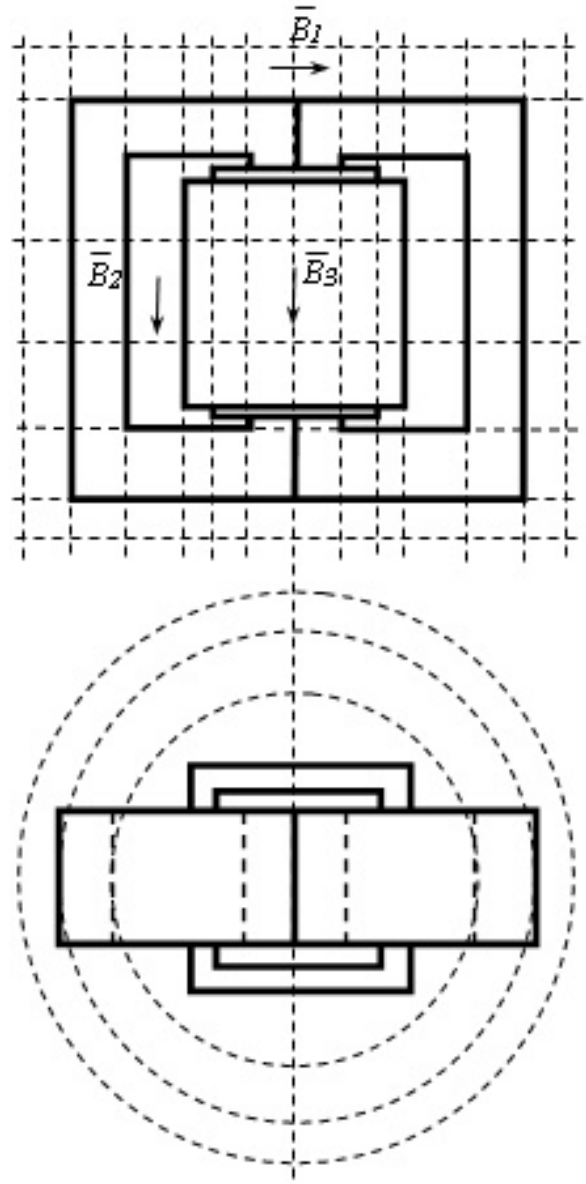

Fig. 1. The scheme of dividing the space of the transformer with an armored magnetic core into elementary volumes.

The field in elementary volumes with a certain approximation can be considered homogeneous and therefore these volumes are given in the magnetic equivalent circuits by lumped magnetic resistances. The magnetic fluxes that pass through elementary volumes are decomposed into vertical and horizontal components (for electromagnetic devices) or tangential and radial components (for electric machines).

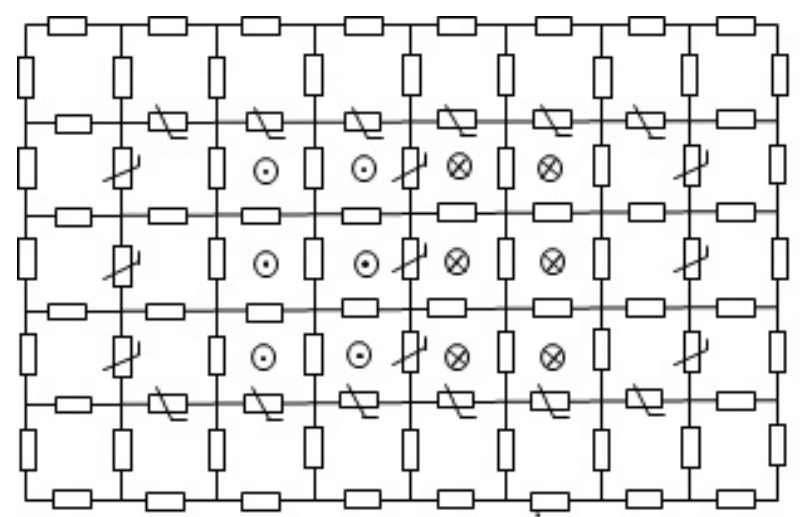

Fig. 2. Diagram of the magnetic circuit of a transformer with an armored magnetic core.

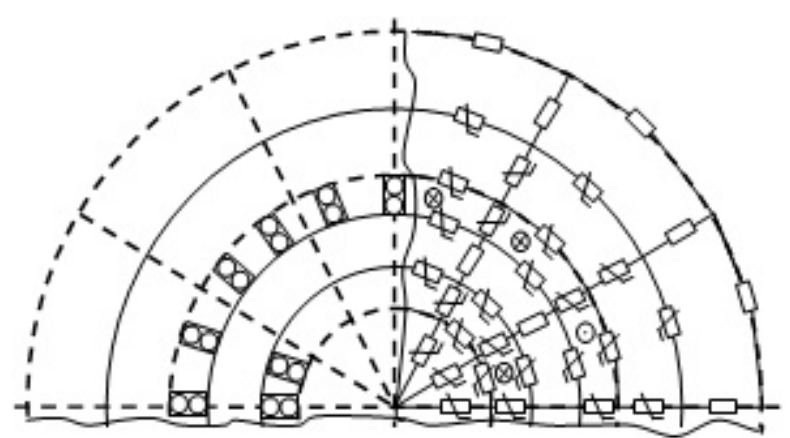

Fig. 3. Synchronous turbogenerator and the scheme of its magnetic circuit.

Based on the average values of geometric dimensions and magnetic characteristics (the main magnetization curve) of the magnetic circuit material, we determine the parameters of magnetic resistances. The nonlinear characteristic of magnetization is approximated by cubic splines.

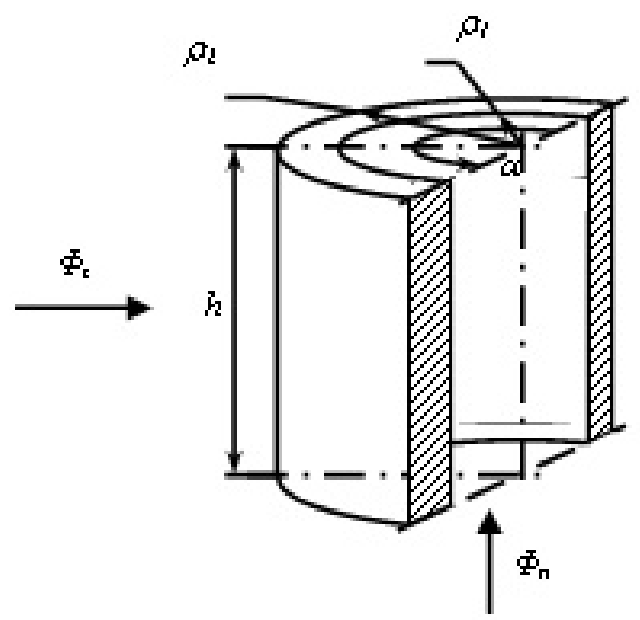

Fig. 4. Elementary volume.

The magnetic fluxes through these volumes of currents pass in the vertical and horizontal directions. Their resistances are determined according to the formulas:

$$
\begin{gathered}
R_{m w}=h /\left(\mu_{\alpha \rho}^{\alpha \rho} \rho d \alpha d \rho\right)=2 h /\left(\mu \pi\left(\rho_{2}^{2}-\rho_{1}^{2}\right),\right. \\
R_{m h}=\int_{\rho_{1}}^{\rho_{2}} d \rho /(\mu h \alpha \rho)=\ln \left(\rho_{2} / \rho_{1}\right) /(\mu h \pi),
\end{gathered}
$$

where $h, \alpha, \rho_{1}, \rho_{2}$ are the geometric dimensions of the elementary volume; $\mu$ is the absolute magnetic permeability of the area of elementary volume.

The magnetic system of electrical devices having been represented by a planar diagram of the magnetic circuit, we developed their mathematical models with 
differential magnetic parameters (DMP) and differential electromagnetic parameters (DEMP).

A mathematical model of electrical devices with DMP in the coordinates of contour magnetic fluxes and branch currents is formed as a system of differentialfinite equations in the following form

$$
\begin{gathered}
\boldsymbol{\Gamma}_{\mathbf{m}} \stackrel{1}{U}_{m}(\Phi)-\mathbf{W}_{t} i=0, \\
\boldsymbol{\Pi}_{\mathbf{e}}^{\prime} i=0, \\
\Gamma_{\mathbf{e}}\left(\mathbf{W} d \dot{\Phi}_{k} / d t+\mathbf{R}^{\prime} i\right)-\boldsymbol{\Gamma}_{\mathbf{e}}^{\prime} u=0,
\end{gathered}
$$

where $\boldsymbol{\Gamma}_{\mathbf{m}}$ is the second matrix of magnetic circuit incidences; $\stackrel{L}{m}_{m}(\Phi)$ represents the vector-column of magnetic voltages of branches; $\mathbf{W}_{t}$ stands for the transposed matrix of turns of elementary circuits of the magnetic circuit (its dimension is determined by the number of loops of the magnetic circuit and the number of windings); $i$ is the vector column of winding currents; $\Pi_{e}, \Gamma_{e}$ are the first and second matrix of electrical circuit incidents;; $\stackrel{1}{\Phi}_{k}$ denotes the vector-column of loop magnetic fluxes; $\mathbf{R}$ is the diagonal matrix of winding resistances; $i, \dot{u}$ are the vectors-columns of winding currents and voltages.

A mathematical model of electrical devices with DEMP in the coordinates of branch currents is formed as a system of differential-finite equations [5]

$$
\begin{gathered}
\boldsymbol{\Pi}_{\mathrm{e}}^{\prime} i=0, \\
\Gamma_{\mathbf{e}}\left(\mathbf{M} d i / d t+\mathbf{R}^{\prime} i\right)=\Gamma_{\mathrm{e}}^{\prime} u,
\end{gathered}
$$

where $\mathbf{M}$ is the matrix of differential electromagnetic parameters of the electrical device.

Matrix $\mathbf{M}$ can be determined from the equation of magnetic circuit (3), pre-differentiating it by current

$$
\mathbf{M}=\partial^{\prime} \Psi / \partial{ }^{\prime} i=\mathbf{W} \partial \Phi^{\prime}{ }_{k} / \partial^{\prime} i=\mathbf{W R}_{\mathbf{m K}}^{-1} \mathbf{W}_{t},
$$

where $\mathbf{R}_{\mathrm{mk}}=\boldsymbol{\Gamma}_{\mathrm{m}} \mathbf{R}_{\mathrm{m}} \boldsymbol{\Gamma}_{\mathrm{mt}}$ is the matrix of loop differential magnetic resistances, $\mathbf{R}_{\mathbf{m}}$ is a diagonal matrix of differential magnetic resistances of magnetic circuit branches.

It is expedient that determination of the vectorcolumn of currents and matrix $\mathbf{M}$ in the mathematical model with DEMP be divided into integration steps.

In mathematical models of dynamic objects, which are electric machines, the elements of the matrices $\mathbf{W}$ and $\mathbf{W}_{t}$ are determined by the rotation coordinate of the rotor $\gamma$. Therefore, the following models are supplemented by equations of motion:

$$
\begin{gathered}
J d \omega / d t+M_{E}+M_{T}=0, \\
\omega=d \gamma / d t,
\end{gathered}
$$

where $J$ is the moment of the rotor inertia; $M_{E}$ is the electromagnetic moment of the machine; $M_{T}$ is the mechanical moment on the rotor shaft; $\omega$ is the angular speed of the rotor; $\gamma$ is the coordinate of the rotor rotation.

The proposed mathematical models of electrical devices with DMP and DEMP are described by nonlinear differential-finite equations. In its implementation, we used the implicit method of backward differentiation formulas for integration, and Newton's method for solving the system of nonlinear equations. To solve the linearized system of the equations, taking into account the peculiarities of the Jacobi matrix, the optimized Gaussian method is used.

In two types of mathematical models of the electrical devices either with DMP or DEMP at each step of integration it is possible to obtain not only the values of branch currents, but also the loop magnetic fluxes of the branched network of the magnetic circuit. This allows us to obtain with a certain approximation of the values that characterize the magnetic field - induction and magnetic field strength.

First, at each step of integration, the loop magnetic fluxes are used to calculate the values of the magnetic fluxes of the branches

$$
\stackrel{\prime}{\Phi}=\Gamma_{\mathrm{mt}} \stackrel{1}{\Phi}_{\kappa} .
$$

Equation (11) allows us to obtain the values of magnetic fluxes in different parts of space for two directions: vertical and horizontal (electromagnetic devices) and radial and tangential (electric machines). To determine the magnitude of the the magnetic field induction in the appropriate directions, we divide the magnetic fluxes by the average values of the cross sections of elementary volumes, the planes of which are perpendicular to the directions of the fluxes

$$
B=\Phi / S,
$$

The resulting vector of magnetic field induction in the general case is defined as the geometric sum of four vectors

$$
\stackrel{r}{B}=\sum_{i=1}^{4} \stackrel{\mathrm{V}}{B_{i}}
$$


For the analytical calculation of the magnitude and direction of the magnetic induction vector at points in space corresponding to the nodes of the branched network of the magnetic circuit, you can use the projection method or the symbolic method. For this purpose it is necessary to give magnetic inductions in the form of complex sizes and then perform operations of addition with them.

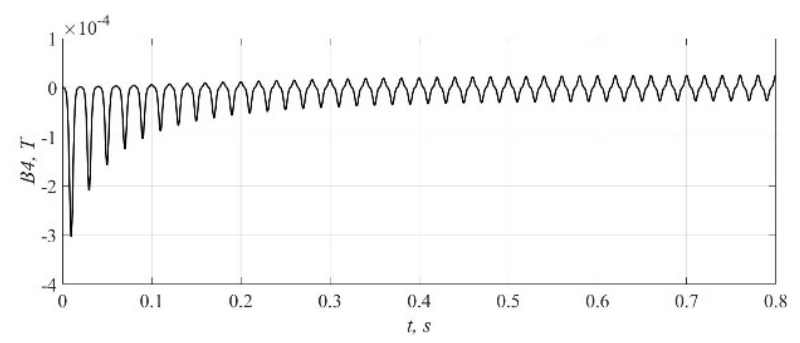

a)

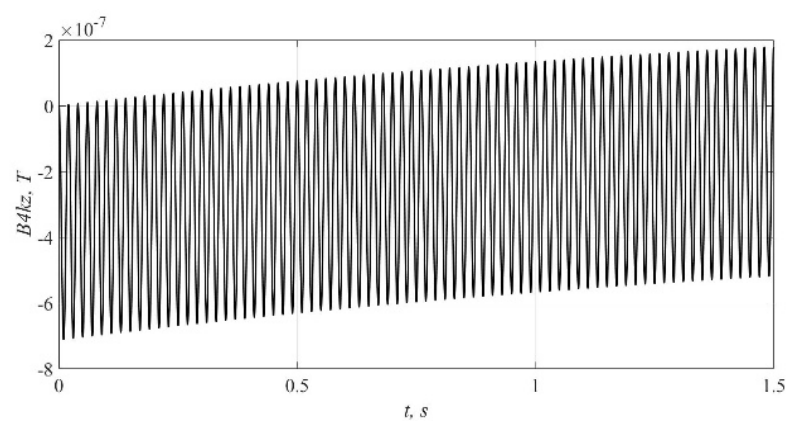

b)

Fig. 5. Magnetic induction over the central rod of the magnetic circuit (B1) during the activation of the transformer in nonoperating mode (a) and the experiment of short circuit (b).

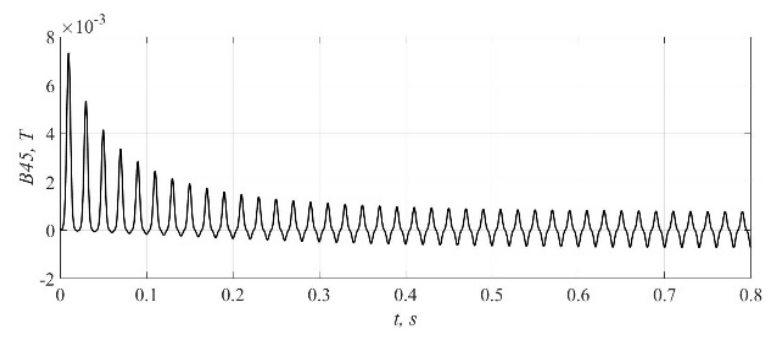

a)

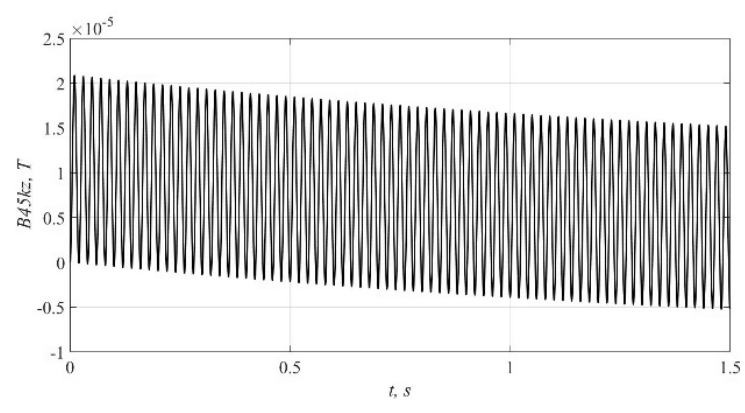

b)

Fig. 6. Magnetic induction between the rods of the magnetic circuit (B2) during the activation of the transformer in nonoperating mode (a) and the experiment of short circuit (b).
A mathematical model of a two-winding transformer with an armored magnetic core design was chosen for mathematical experiments. Comparison of the integrated parameters obtained by modeling with the passport data of the transformer (magnetizing current, short-circuit voltage) confirmed the adequacy of the developed circuit model with DEMP.

For this transformer, switching on process in the nonoperating mode at the nominal voltage and the short-circuit experiment - switching on the short-circuit voltage were simulated. For such modes, the values of magnetic induction in the characteristic directions for some points in the space of the device under study were determined. Some results of the mathematical experiments are presented in Fig. 5-7.

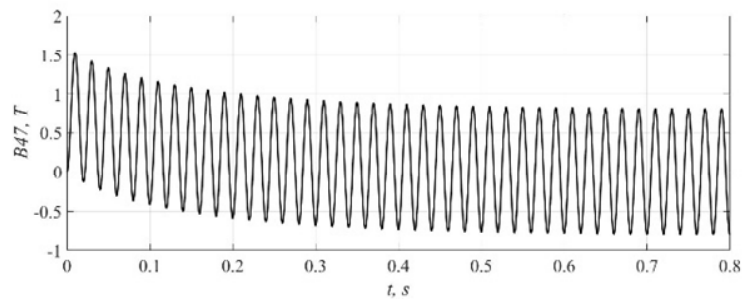

a)

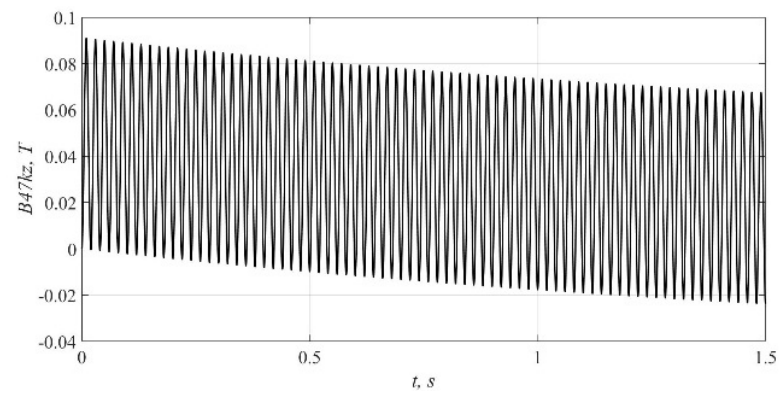

b)

Fig. 7. Magnetic induction in the central core of the magnetic circuit (B3) during the activation of the transformer in non-operating mode (a) and the experiment of short circuit (b).

\section{Conclusions}

The proposed approach using universal high-efficiency (economical and adequate) circuit mathematical models of electrical devices based on a single magnetic flux allows us to calculate not only currents and voltages for different modes, but also to analyze their magnetic fields to determine the magnitude and direction of the magnetic induction vector in any space point.

\section{References}

[1] V. Perkhach, T. Shelepeten, end V. Horyachko, "Digital quasi etalon model electromagnetic devices // Mathematical modeling of electrical engineering, electronics and power", in Proc. 3rd International Conference on Matematychne modeliuvannia $v$ elektrotekhnitsi, elektronitsi ta energetytsi, pp. 208209, Lviv, Ukraine: Lviv Polytechnic National University, 1999. (Ukrainian) 
[2] M. V. K. Chari and P.Silvester, Analysis of turboalternator magnetic fields by finite elements, IEE Trans., PAS-90, pp. 454-464, 1971.

[3] V. V. Vakhnina, V. N. Kuznetsov, and O. V. Samolina, "Modelling of a power transformer magnetic field", Modern problems of science and education, no. 2-1, 2015. URL: http://www.scienceeducation.ru/ru/article/view?id=

[4] P. Stakhiv, O. Hamola, V. Horyachko, and T. Grywacz, "Mathematical Model of a Transformer with Differential Electromagnetic Parameters", in Proc. 19th International Conference Computational Problems of Electrical Engineering, IEEE. Banska Stiavnica, Slovak Republic, pp. 1-4, 9-12 September 2018.

[5] V. Horyachko, O. Hamola, and T. Ryzhyi, "Calculation of Windings Differential Inductances of Electrical Devices in Mathematical Models with a Total Magnetic Flux", Proceedings of 2020 IEEE 21st International Conference on Computational Problems of Electrical Engineering, CPEE 2020, 2020, 9238713.

\section{АНАЛІЗ МАГНІТНИХ ПОЛІВ ЕЛЕКТРОТЕХНІЧНИХ ПРИСТРОЇВ НА ПІДСТАВІ ЇХ КОЛОВИХ МОДЕЛЕЙ}

\author{
Всеволод Горячко, \\ Орест Гамола, Тарас Рижий
}

Запропоновано аналіз магнітних полів електричних машин i електромагнітних апаратів на підставі їх колових математичних моделей. Магнітні системи електротехнічних пристроїв у цих моделях подано у вигляді планарних нелінійних магнітних кіл зі зосередженими елементами. Параметри цих елементів визначено на підставі геометричних розмірів 3 врахуванням конструктивних особливостей пристроїв та фізичних параметрів середовища.

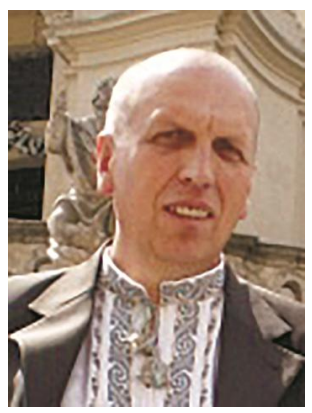

Vsevolod Horyachko - PhD, Ass. Professor, graduated from Biological Faculty of Ivan Franko State University of Lviv and Electric Power Engineering Faculty of Lviv Polytechnic Institute, Ukraine. He received his $\mathrm{Ph} . \mathrm{D}$. degree in the field of theoretical electrical engineering. Since 1983 he has been working at the Department of Theoretical Electrical Engineering at Lviv Polytechnic National University; author of numerous publications in scientific journals and conference proceedings.

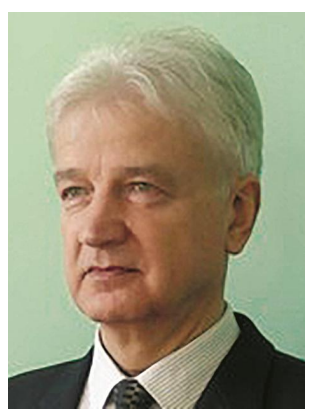

Orest Hamola - PhD, Ass. Professor, graduated from Electromechanical Faculty of Lviv Polytechnic Institute, Ukraine in 1979. $\mathrm{He}$ received his Ph.D. degree in the field of theoretical electrical engineering. Since 1995 he has been working at the Department of Theoretical Electrical Engineering at Lviv Polytechnic National University, Ukraine. His scientific interests are focused on mathematical modelling of electric circuits and electromechanical converters.

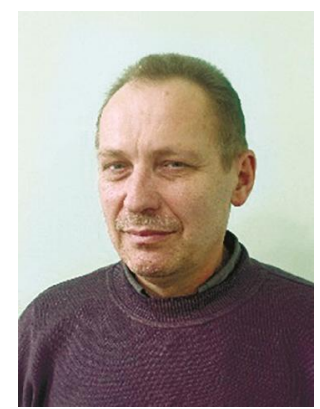

Taras Ryzyi - Senior Lecturer, graduated from Electric Power EFgineering faculty of Lviv Polytechnic Institute, Ukraine. Since 1983 he has been working at the Department of Theoretical Electrical Engineering at Lviv Polytechnic National University.

Received: 12.03.2021. Accepted: 15.05.2021 